Article

\title{
Comprehensive Assessment for Post-Disaster Recovery Process in a Tourist Town
}

\author{
Byungyun Yang ${ }^{1}$ and Israt Jahan ${ }^{2, *}$ \\ 1 Certified Mapping Scientist and Professional Engineer, Department of Geography, DePaul University, \\ 990 West Fullerton Avenue, Suite 4513, Chicago, IL 60614, USA; byang15@depaul.edu \\ 2 Department of Urban and Regional Planning, Chittagong University of Engineering \& Technology, \\ Chittagong 4349, Bangladesh \\ * Correspondence: ijahan@udel.edu; Tel.: +1-302-333-5556
}

Received: 3 April 2018; Accepted: 25 May 2018; Published: 2 June 2018

\begin{abstract}
This paper develops a comprehensive assessment of post-disaster housing and tourism resource recovery. It enables us to address how many natural and man-made features in a tourist town have recovered after a hurricane event. The assessment uses a variety of sources, at different spatial scales and at different points in time. Furthermore, this study develops a measurement scale to quantify damage and recovery appropriate for the available resources. In particular, the study focuses on the development of a methodological approach to tracking housing and tourism resource recovery and helping local communities recover faster the damaged areas after disaster. The effort uses multiple sources of data, including questionnaire data, Federal Emergency Management Agency (FEMA) damage data, airborne light detection and ranging (LiDAR) data, and remote sensing satellite images. The data are quantitatively analyzed to fulfill the objectives of assessing housing recovery rate over time and are represented on maps. The maps are used to represent the status of damaged buildings (e.g., no damage, minor or major damage, affected or destroyed). Furthermore, repaired buildings in specified time intervals are represented on the maps. Eventually, this study develops two schematic diagrams illustrating the average damage and the weighed recovery from multiple data sources. The outcomes of this study will help decision makers emphasize on the locations identified as experiencing differential progress in the reconstruction, rebuilding, and repairing of houses or tourism resources.
\end{abstract}

Keywords: disaster management; housing recovery; GIS; LiDAR; public involvement

\section{Introduction}

Coastal zones, and particularly beach areas, attract tourism. They have recreational and ecotourism opportunities and provide multiple economic values to people as spaces for residence or outdoor recreation [1]. Despite their many benefits, coastal communities with large populations are at high risk due to increased vulnerability to sea level rise, regular flooding, coastal erosion, and potential damage from tropical and extra-tropical storms. Such a devastating event occurred on 29 October 2012, 25 August 2017, and 10 September 2017, when Hurricanes Sandy, Harvey, and Irma hit the east coast, Texas, and the Florida coast in the United States, respectively. Sandy caused $\$ 30$ billion in damage, and damaged or destroyed 346,000 homes in New Jersey. Harvey and Irma caused \$100 and $\$ 190$ billion in economic damage, respectively. Such destruction from hurricanes greatly impacts the tourism in coastal areas. The tourism industry is more vulnerable to the prevalence of disasters than other industries. Thus, tourism towns near coastal areas are sensitive to the recovery process or redevelopment following major storms. For these reasons, the tourism industry requires continuous 
efforts to develop collaborative relationships among different organizations to accelerate the recovery process [2].

The severity of hurricane impact makes the recovery process long, time-consuming, and costly. For example, even two years after Hurricane Sandy, the local infrastructure was still recovering and rebuilding [3]. Rebuilding damaged homes was a large portion of the recovery process, and accelerates the physical recovery process of the impacted area by helping households or tourists return to their regular activities [4]. Therefore, rebuilding needs to be planned and implemented adequately to ensure quick recovery. The first challenge in housing recovery is correctly estimating the damage [5]. Depending on the level of damage, several decisions regarding financial assistance at federal, state, and local levels must be made. Estimating the damage is not limited to housing, but includes all tourism resources such as hotels, resorts, and sandy beaches. Furthermore, the recovery process needs exact and prompt assessment of the damaged properties, which requires multiple publicly-available data sources. These data sources then need to be integrated into the recovery process. This integrated information needs to be provided to the people or tourists who live there or visit the tourism attractions. Helping people spatially understand the damaged areas at a local scale decreases the recovery period in damaged coastal areas. That is, proper damage estimates will accelerate the recovery process. Damage estimates can also help keep track of those locations' progress in recovery. While impacted areas are still recovering from the hurricane damages, it is important to track the rate of recovery.

This research develops a comprehensive assessment method for post-disaster housing and tourism resource recovery using public opinion. This method helps us to track housing recovery and approach the quick recovery of damaged areas based on permanent housing conditions. The proposed assessment used a variety of sources, at different spatial scales and at different points in time. Multiple sources were used to develop a comprehensive measurement scale to quantify damage and recovery: questionnaire data, Federal Emergency Management Agency (FEMA) damage data, airborne light detection and ranging (LiDAR) data, and remote sensing images. Data were analyzed quantitatively to fulfill the objectives of assessing housing recovery rate over time. Maps were used to compare the status of damaged buildings damaged from disasters (e.g., no damage, minor or major damage, affected or destroyed) and repaired buildings required over specified time intervals based on available data. These findings in this study will help policy makers, emergency managers, coastal managers, decision makers, and other professionals to identify the locations experiencing differential progress in the reconstruction, rebuilding, and repairing of houses, and to take necessary actions to help those locations to accelerate their recovery process.

This paper is structured as follows: Section 2 describes previous studies related to the recovery of housing and tourism resources, and introduces the study area. Section 3 includes data collection and the primary research approaches; Section 4 provides the final outputs resulting from the primary methods; and Section 5 discusses the significant contributions and limitations of this research, and Section 6 concludes the paper.

\section{Related Work and Study Area}

\subsection{Literature Review}

Faulkner [6] stated that an increasing number of disasters affect the tourism industries. Particularly, coastal areas have long been recognized as major tourism attractions, making these tourism areas more vulnerable to coastal disasters. To promptly recover damaged properties or tourism resources, it has been necessary to have a collaborative relationship with the public and private sectors.

Recovery involves the repairing, redevelopment, reconstruction, improvement of the damaged, destroyed or existing physical property with the social, economic and natural environment [7] for the betterment of the community and to be prepared for future events. Depending on scale, the damage level and recovery progress differs, so each event needs to be analyzed individually [8]. 
Researchers have applied a variety of measures or indicators to capture different dimensions of household or family recovery, such as psychological or perceptional measures related to stress, sense of loss, and regaining income, employment, household amenities, household assets, etc. [4]. Residents and public officials considered completed reconstruction and improved living standards as recovery indicators after the five-year reconstruction plan of the Chi-Chi Earthquake. In areas with economic growth, post-disaster reconstruction was more important [9].

Recovery is very difficult to measure, because it is multi-dimensional, time consuming, and complex. Recovery is the most challenging and uncertain part of disaster management $[5,10,11]$. In related literature, there is no cohesive definition of recovery. Studies related to disaster recovery were very limited prior to the 1970s [12,13]. Haas [14] first studied community-level disaster recovery in the late 1970s. Community-level disaster recovery received more attention by the mid-1980s, when case studies at the local level were considered to be the basis for describing the recovery process [8,14-16]. Although a number of recovery indicators have been studied for different aspects of disaster recovery (e.g., environmental [17,18], social [4,16,19], economic [20], political [21,22], housing [9,23], sustainable recovery $[7,17]$, disaster resilience $[8,13]$, and many others), the recovery phase is still considered as the most critical, the least understood, and the least researched indicator among the different phases of disaster management $[7,8,20,24]$. Disaster recovery begins after the initial disaster. The disaster response phase continues for years, sometimes over decades, depending on the severity of the initial disaster or until the next disaster affects the same area $[4,5,10,11]$. Most of the previous research in disaster recovery covered a limited period of time or a single point in time [15,25]. A long-term disaster recovery evaluation is required to understand the post-disaster recovery process [25,26], as it is difficult to identify post-event changes immediately [27]. Long-term recovery addresses rebuilding or relocating damaged or destroyed social, economic, natural, and built environments, along with other factors [28]. It is necessary to monitor both the recovery speed and quality [8].

Several studies have applied different techniques to study post-disaster recovery. Rathfon et al. [11] studied the physical properties of permanent houses in the hurricane-affected area of Punta Gorda, Florida to measure the housing recovery as part of household recovery. Kaku, Aso, and Takiguchi [29] applied high-resolution satellite images to assess the post-earthquake conditions at the local level in East Japan. Morgan et al. [30] used a questionnaire survey of residents to monitor earthquake recovery in Canterbury, England. Additional studies examined building permit data (repaired or demolished then rebuilt) [11,31], tax appraisals, land-use changes and census data [32], remote sensing satellite images [33,34], geo-referenced geographic information systems (GIS) maps [32,35], occupancy certificates, property appraisals, property sales, FEMA's temporary housing data, temporary roof installation by US. Army Corps of Engineers [11], and more to measure the level of recovery.

In terms of the research gaps in the above literature review, our study combined and compared several of these methods, covering the response of residents along with geospatial information to evaluate disaster recovery at the local community level. Particularly, this paper emphasizes the development of a comprehensive methodological approach combining data from different sources of spatial data and from questionnaire data to track housing recovery and explore the rate of progress in the reconstruction/repair/reshaping of damaged buildings as an indicator of housing recovery in one of the areas affected by Hurricane Sandy. To fulfill the purpose, the borough of Sea Bright in Monmouth County of New Jersey was selected for detailed study.

\subsection{Sea Bright, New Jersey}

A detailed study was done in the borough of Sea Bright, in Monmouth County, New Jersey, to explore damages from Hurricane Sandy and the subsequent state of their recovery progress. Sea Bright is a barrier island of approximately 0.64 square miles with water bodies on two sides of the land (Figure 1c). The main industry of the town is tourism, which drives the restaurant and beach club businesses. According to Dr. McNeil's research (2016), approximately 30 residents work in 
the town, and approximately 450 travel into Sea Bright for work [36]. The land is physically vulnerable and historically susceptible to severe and recurrent coastal storm damage, with regular flooding. Thus, the tourism industry in the town is also vulnerable to coastal disasters. During Hurricane Sandy, Sea Bright was within the 100 to $120 \mathrm{~km}$ buffer zone from the nearest trajectory of the hurricane eye (Figure 1d). This area experienced massive devastation from Sandy. Hurricane Sandy had major negative impacts on homeowners, renters, and businesses in Sea Bright. In the immediate aftermath of the hurricane, there were six feet of sand on the main road, Ocean Avenue, and many community facilities were destroyed. FEMA records show that 759 structures were damaged in Sea Bright [37], while the US Department of Housing and Urban Development (HUD) shows 720 structures damaged in Hurricane Sandy and the first floor of 376 buildings had four feet of flooding. Of the homes damaged, 360 were owner-occupied and 360 were rental properties [38]. Damage estimates were approximately $\$ 391$ million. The sea wall, built to protect against storm surge, was damaged in many places.

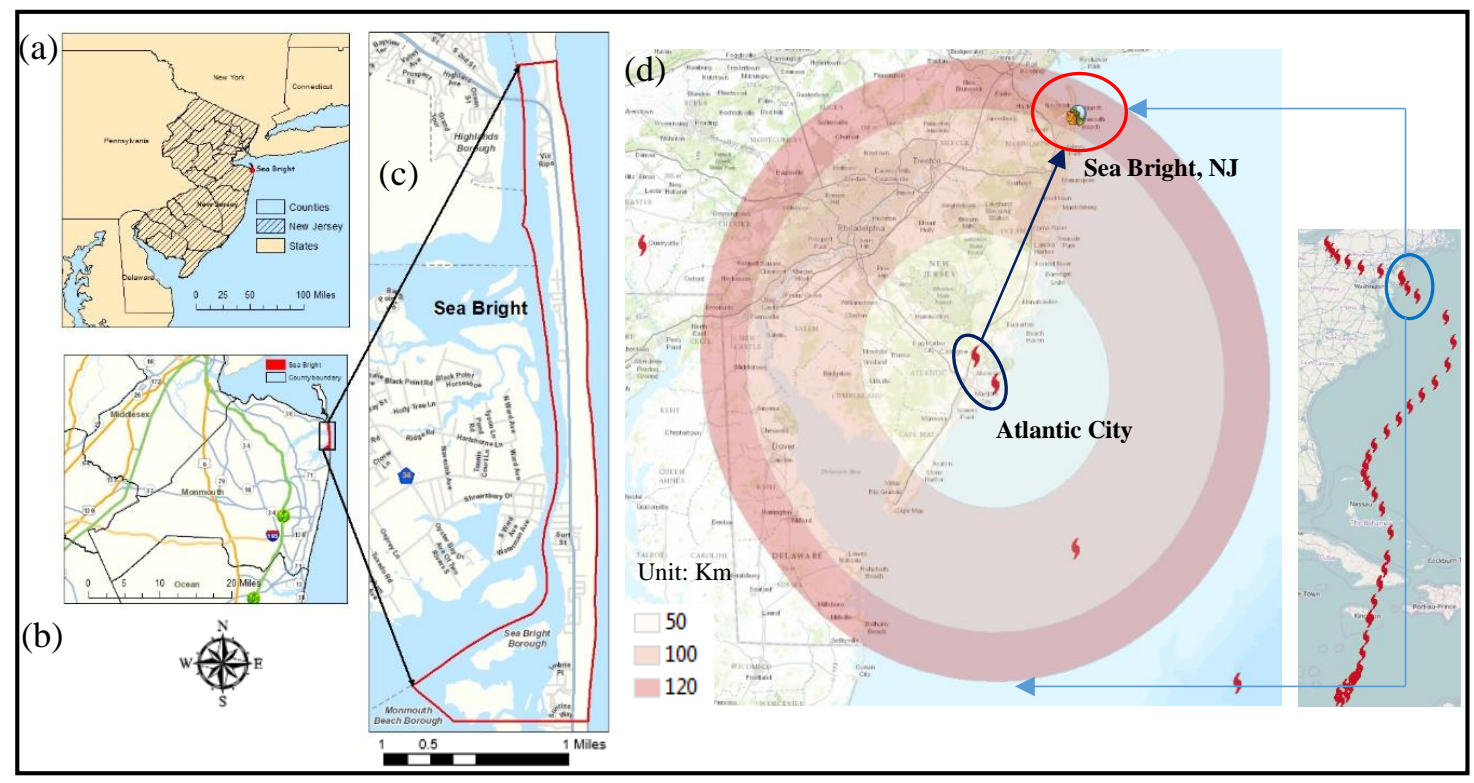

Figure 1. Study area (a: New Jersey; b: Monmouth county; c: Sea Bright; d: Hurricane Sandy).

\section{Methods}

\subsection{Developing Workflow and Data Collection}

Our research assembles and uses data from different sources and then integrates these data to document the recovery of damaged properties over time. The recovery rates, over time, of damaged structures in the affected area were studied based on quantitative methods supported by the literature. Figure 2 shows the schematic diagram of our workflow.

First, this research used mail-based survey data provided by the Disaster Research Center at the University of Delaware. The mail-based questionnaire was designed, approved by their Institutional Review Board (IRB), and implemented in 2014 to collect information related to damage from Hurricane Sandy and people's perception of issues related to recovery and resettlement. The 303 responses from Sea Bright, New Jersey households were recorded from the survey, and incorrect or unreachable addresses were not counted. The questionnaire included 75 questions. Here, only data relevant to the research questions were considered for analysis. These data included the ownership of the property (own/rent), type of home, property status immediately after Sandy, present condition (abandoned/repair completed/repair in progress/rebuilt/demolished/repair scheduled to begin/property sold/property for sale, etc.), mitigation measures applied in rebuilt properties, source(s) of funds, damage estimates in dollars, and household income variation. In the 
questionnaire, the respondents were asked to comment on the level of damage to their homes and their community using a Likert-type scale, ranging from "no damage" to "very extensive damage" on a four-point base. The survey also provided numerical values for the damage estimates.

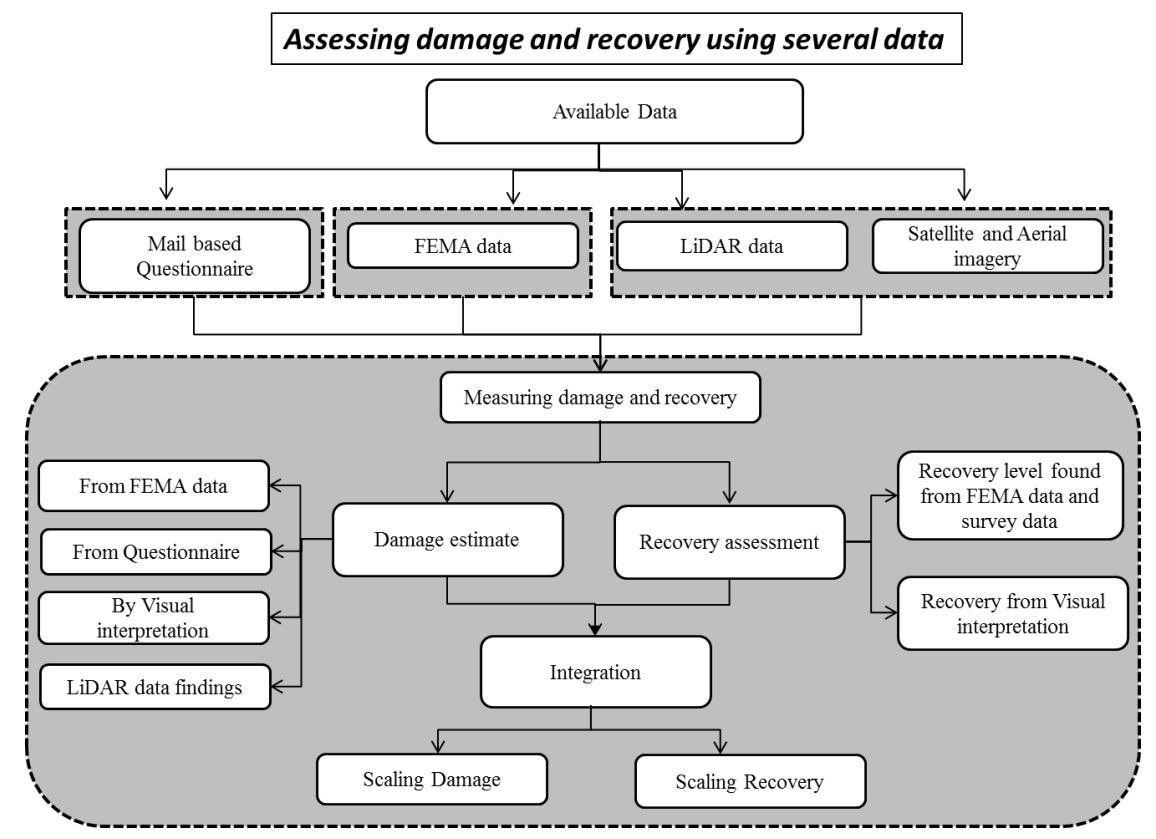

Figure 2. Schematic diagram of workflow. FEMA: Federal Emergency Management Agency; LiDAR: light detection and ranging.

Second, the FEMA Modeling Task Force (MOTF) report, published in 2014, contains detailed information on the damage caused by Hurricane Sandy. It includes measures of the immediate damage level, inundation data, and other impact data, presented in tabular, report, and geographic information system (GIS) data. For this research, only MOTF data related to Sea Bright, from FEMA's larger database, were extracted and compared with other data sources. To determine the number of impacted residential buildings more accurately, FEMA-MOTF identified households in the exact same location as multi-family residential buildings and applied the maximum household damage classification for the entire building. Other data included in damage estimates were visible damage from aerial imagery and inundation-based damage assessment. These data provide more comprehensive estimates in addition to considering households that applied for FEMA assistance. FEMA-MOTF classified building damage as affected, minor or major damage, and destroyed. The criteria of our classification were:
i. $\quad$ Affected-total full verified loss (FVL) $\$ 0$ to $\$ 5000$
ii. Minor-total FVL $\$ 5000$ to $\$ 17,000$
iii. Major-total FVL more than $\$ 17,000$
iv. Destroyed-if indicated by Individual Assistance (IA) inspector

This information was updated combining the visible damage in imagery, water inundation depth, and FEMA-MOTF observation. Finally, the combined damage data in the FEMA-MOTF report showed more accurate and detailed damage conditions. These values were used for the damage estimation in the study area.

Airborne LiDAR data are a more accurate, high-resolution, and precise data source, and were used to provide geospatial information on housing conditions for both pre- and post-disaster conditions. LiDAR point clouds can capture the immediate hurricane impact. Pre- and post-disaster data were compared to visually interpret the extent of the damaged sites. Change in elevation indicates structural damage with loss or gain. LiDAR data from the United States Geological Survey (USGS) and the 
National Oceanic and Atmospheric Administration (NOAA) covering only the study area were downloaded for detailed analysis. The USGS produced LiDAR point cloud data from remotely-sensed geographically referenced elevation measurements. They used second-generation Experimental Advanced Airborne Research Lidar (EAARL-B, a pulsed laser) in an aircraft to measure ground elevation, vegetation canopy, and coastal topography of the target area. The approximate travel speed and flight height was $55 \mathrm{~m}$ per second and $300 \mathrm{~m}$, respectively, resulting in a laser swath of approximately $240 \mathrm{~m}$ with an average point spacing of 0.5 to $1.6 \mathrm{~m}$. Data acquisition dates were 26 October 2012, prior to Hurricane Sandy, and 1 and 5 November 2012, just after landfall in New Jersey. These data were published on 3 June 2014. USGS and NOAA initiated this project to produce accurate and highly-detailed digital elevation maps serving the needs of researchers. These LiDAR data were referenced to the Universal Transverse Mercator (UTM) projection Zone 18N, horizontal datum "NAD 1983", and vertical datum "NAVD 1988" in units of meters.

Fourth, aerial images in four time periods $(2010,2012,2013$, and 2016) were collected to visually inspect land use change by comparing pre-Sandy and post-Sandy events. NOAA also conducted aerial photography of the east coast, Hurricane Sandy affected areas on the day following landfall. FEMA published their aerial images in 2014. In addition, Google-Earth satellite images are available in a time series, including years 2010, 2012, 2013, and 2016. These data were assembled to spatially compare the damage scenario of physical properties as an element of housing recovery through change detection. Tourism resources such as sandy dunes or beaches were also visually compared for change detection.

\subsection{Measuring Damage and Recovery}

As shown in Section 3.1, data from different sources were collected and analyzed to allow for research using three time frames: before Sandy, immediately after Sandy, and two years after the event. Data used for measuring housing recovery came from several potential sources, and used different time periods. One of our challenges was to integrate these disparate data. Maps were produced and compared using survey data, remote sensing data, and LiDAR data to identify their variation over time. These maps used the same geographic scale, but various spatial analysis techniques (e.g., overlay, etc.) were used for further analysis. These data were also analyzed statistically with MS Excel, by creating tables and graphs to compare features. For the statistical analysis of these data, percentage change, change in numerical values, were utilized to have more robust and reliable results.

ArcGIS for Desktop was used to create maps and perform spatial analysis. The survey responses were geocoded to spatially represent their locations. After geocoding, data from the survey were imported to an attribute table including individual household responses. The spatial analyst tool in the GIS application was utilized to identify locations with damage and differential recovery progress of recovered, unrecovered, less-recovered, or continuing recovery, and to then compare recovery at certain time intervals. Google Earth satellite images and other aerial images from different time periods were compared by overlaying them, and then by swiping the target image over the base imagery. This technique identified spatial change, over time, after Hurricane Sandy. In the case of LiDAR data, the change detection was computed using Quick Terrain Modeler software to identify the damage location with color codes and values in elevation change.

Finally, this technique produced the number and percentage of houses repaired, rebuilt, or reconstructed by showing the change over time, to indicate recovery from the damage at the time of disaster to the present situation. These findings are presented in maps, charts, and tables to illustrate a comparative view over time. This map series shows the areas experiencing changes in housing recovery or tourism resources and compares their progress. In order to compare the progress, we calculated and weighted the impacts of damage using several data in charts. It was computed by the following equation.

Impact of damage $=($ No. of Properties with specific damage $\times$ Weight $) /$ Total damaged property. 
Furthermore, this research also scaled recovery progress using multiple data in order to assess the average recovery for the entire community and in a specific area. The following equation was used to calculate impact value of properties:

Impact value of properties $=($ No. of Properties still need repair with specific damage $\times$ Weight $) /$ Total damaged property.

Some graphs show trend lines with decreasing or increasing patterns, illustrating the relationship between destroyed property and occupancy of the plot post-Sandy. These graphs use 2012 as the base year of pre-hurricane occurrence. The government and other organizations related to housing recovery could use these maps to identify and improve locations experiencing slow recovery from disasters.

The detailed information in terms of the impact damage and the impact value of properties are addressed in Sections 4.1.2 and 4.1.3, respectively.

\section{Results}

\subsection{Damage to Structures}

The structural damage by Hurricane Sandy was studied from several data sources. These data were integrated to compare the view and have a more specific sense of the damage distribution. The following subsections describe the findings from analysis to describe the damage pattern in Sea Bright, New Jersey.

\subsubsection{Damage Estimates from FEMA Data and Questionnaire}

According to FEMA-MOTF, 2014, Sea Bright falls within the very high impact area for Hurricane Sandy. This report shows storm surge as the primary reason for the severe impact by Hurricane Sandy. Among the impacted structures, $71.8 \%$ had damage due to inundation alone. The water height recorded in FEMA-MOTF ranged from approximately 0.04 feet to 12 feet. According to USGS survey data, at five locations in Sea Bright, high water marks were 4-5.1 feet above ground level [4].

Table 1 combines and compares the findings from the questionnaire and FEMA-MOTF damage data to create a comprehensive damage scenario of this location. Among the 303 households that responded, $68.89 \%(37.79 \%+31.10 \%)$ of the total area experienced extensive damage (including both somewhat and very extensive damage), while considering the identified response within the study area (i.e., of 180 responses) it was $70.22 \%(38.20 \%+32.02 \%)$. However, comparing the damage condition to the FEMA-MOTF data shows that $87.78 \%(47.78 \%+38.33 \%+1.67 \%)$ of the damaged area experienced minor to complete destruction. Thus, these data proved consistent with each other.

Table 1. Damage to home from survey responses and FEMA Modeling Task Force (FEMA-MOTF) data on respective location.

\begin{tabular}{|c|c|c|c|c|c|c|c|c|c|}
\hline \multirow[t]{2}{*}{$\begin{array}{l}\text { Damage } \\
\text { Level }\end{array}$} & \multicolumn{2}{|c|}{$\begin{array}{l}\text { All Responses } \\
\text { from the Survey }\end{array}$} & \multicolumn{2}{|c|}{$\begin{array}{c}\text { Response } \\
\text { Addresses Located } \\
\text { Only in Sea Bright }\end{array}$} & \multirow[t]{2}{*}{$\begin{array}{l}\text { Damage } \\
\text { Level }\end{array}$} & \multicolumn{2}{|c|}{$\begin{array}{l}\text { FEMA-MOTF Data } \\
\text { Corresponding to the } \\
\text { Response in Sea Bright }\end{array}$} & \multicolumn{2}{|c|}{$\begin{array}{c}\text { FEMA-MOTF } \\
\text { Data for Entire } \\
\text { Sea Bright }\end{array}$} \\
\hline & $\mathrm{n}$ & $\%$ & $\mathrm{n}$ & $\%$ & & $\mathbf{n}$ & $\%$ & $\mathrm{n}$ & $\%$ \\
\hline No Damage & 20 & 6.69 & 7 & 3.94 & Affected & 22 & 12.22 & 108 & 14.23 \\
\hline $\begin{array}{l}\text { Not Very } \\
\text { Extensive }\end{array}$ & 73 & 24.42 & 46 & 25.84 & Minor & 86 & 47.78 & 252 & 33.2 \\
\hline $\begin{array}{l}\text { Somewhat } \\
\text { Extensive }\end{array}$ & 113 & 37.79 & 68 & 38.20 & Major & 69 & 38.33 & 381 & 50.2 \\
\hline $\begin{array}{c}\text { Very } \\
\text { Extensive }\end{array}$ & 93 & 31.10 & 57 & 32.02 & Destroyed & 3 & 1.67 & 18 & 2.37 \\
\hline Total & 299 & 100 & 178 & 100 & Total & 180 & 100 & 759 & 100 \\
\hline Missing & 4 & & 2 & & & & & & \\
\hline
\end{tabular}


Figure 3 spatially compares survey response results and FEMA data with respect to damage conditions perceived by the households and as assessed by FEMA. The map shows that the southern part of the island experienced more damage regarding major, minor, and destroyed structures than the northern part of the island. While the northern section had no destroyed buildings, the damage is not negligible, because there were many structures with major and minor damage.

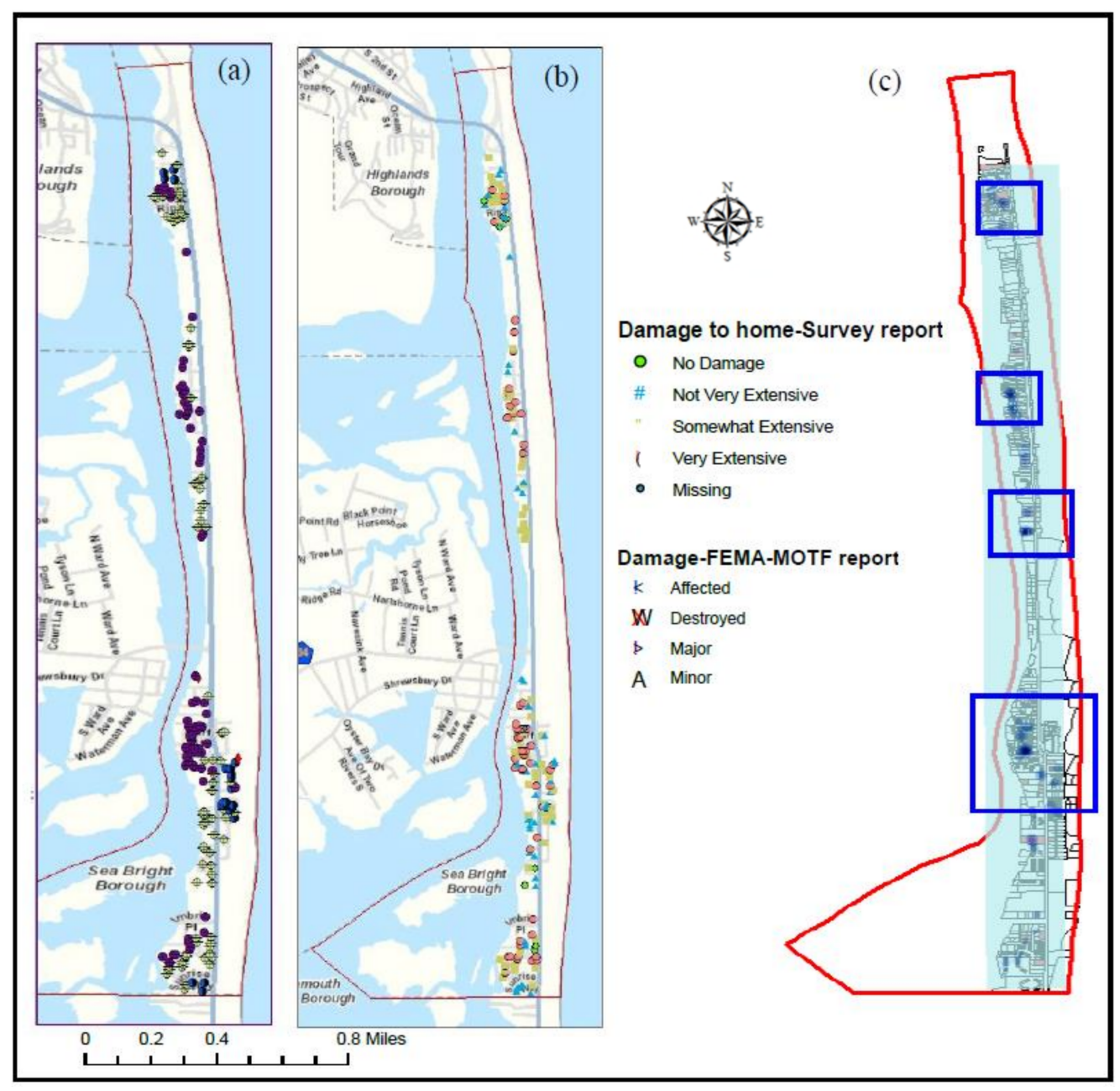

Figure 3. Damage condition recorded from (a) the questionnaire; (b) the FEMA-MOTF data; and (c) the distribution of estimated damage from the survey in kernel density analysis.

Based on the damage estimates from survey responses, kernel density analysis was performed to create a continuous surface surrounding damage concentrations based on people's perception. Here damage cost in dollars was the count or quantity to be spread across the landscape. Kernel calculates a magnitude per unit area using a kernel function to fit a smoothly tapered surface to each point or polyline. Figure 3 also highlights the area with more damage concentration as the southern section of Sea Bright.

\subsubsection{Scaling Damage Using Multiple Data}

To explore the range and variability in the damage data, the damage categories were scaled to create a picture of on an "average" scenario for the whole study area. The values were chosen arbitrarily, but based on the severity of the damage. That is, "no damage" had a value of 0, "only affected" had a value of 1, "minor" and "major" damage had values of 2 and 3, respectively, and "destroyed" had the largest value of 4 . Among the 279 responses (excluding no damage and missing data) from the 
questionnaire, the weight of the damage was readjusted such that "not very extensive" damage was weighted as 1, "somewhat extensive" damage as 2.5 , and "very extensive" damage as 4.

For each category of damage, the product of the number in that damage type with their value divided by the number of total damaged properties represents the impact of damage. These resulting values were summed to find the average damage value for the study area. This research used the equation introduced in Section 3.2, which calculates the weighted value. The weighted value with the number of structures under specific damage criteria are listed in Table 2. In order to compute the weighted damage in each level, their weights were added to quantify the damage level of the overall community of Sea Bright. Damage data from FEMA-MOTF for the entire locality and for the location of the survey responses within Sea Bright are shown in parallel in Table 2. The grand totals of weighted damage values, in both cases, were very similar, 2.41 and 2.29, respectively, whereas the resulted average weighted value from the survey data for the entire community was found to be 2.6.

Table 2. Quantifying damaged property to estimate the damage level of the study area using FEMA data for the whole area and survey-responded locations within study area and the category in survey responses.

\begin{tabular}{|c|c|c|c|c|c|c|c|c|c|}
\hline \multicolumn{6}{|c|}{ FEMA Data for Whole Area and Survey-Responded Locations } & \multicolumn{4}{|c|}{ Response Category in Survey } \\
\hline Damage Type & \multicolumn{2}{|c|}{$\begin{array}{c}\text { No. of Damaged } \\
\text { Properties }\end{array}$} & Scale & \multicolumn{2}{|c|}{ Impact of Damage } & Damage Type & $\begin{array}{l}\text { No. of } \\
\text { Damaged } \\
\text { Properties }\end{array}$ & Scale & $\begin{array}{l}\text { Impact on } \\
\text { Properties }\end{array}$ \\
\hline Affected & 22 & 108 & 1 & 0.12 & 0.14 & No Damage & 20 & 0 & 0 \\
\hline Major & 69 & 381 & 3 & 1.15 & 1.51 & $\begin{array}{l}\text { Somewhat } \\
\text { Extensive }\end{array}$ & 113 & 2.5 & 1.01 \\
\hline Destroyed & 3 & 18 & 4 & 0.96 & 0.09 & Very Extensive & 93 & 4 & 1.33 \\
\hline Total & 180 & 759 & & 2.29 & 2.41 & Total & $\begin{array}{c}279 \text { (excluding } \\
\text { no damage) }\end{array}$ & & 2.6 \\
\hline
\end{tabular}

The average values found from FEMA damage data for whole study area, survey responses within the study area along with damage data, and the overall survey are shown schematically in Figure 4. From this diagram, it is obvious that, on average, the whole community experienced minor to major damage. This result illustrates the importance of selecting Sea Bright as the primary study area for assessing recovery over time.

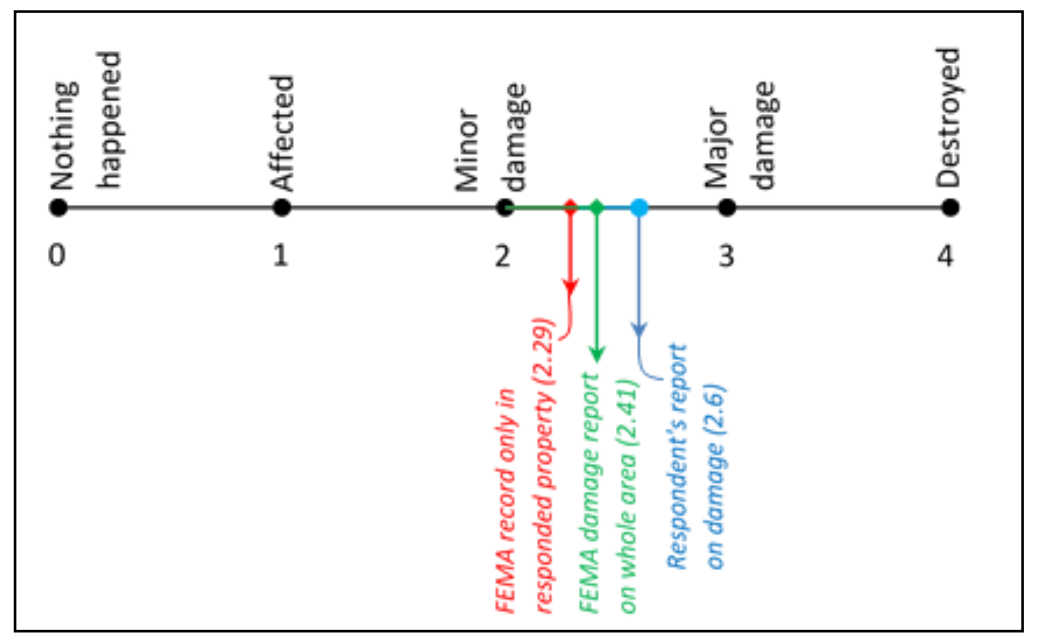

Figure 4. Schematic diagram showing the average damage from different data sources. 


\subsubsection{Visual Interpretation for Tourism Resources}

Aerial and satellite images were visually inspected to detect changes and identify the locations with differential land use, including both man-made and natural features. Figures 5 and 6 show the full view of the study area and a large view of a small area's changes, over time, to illustrate context.

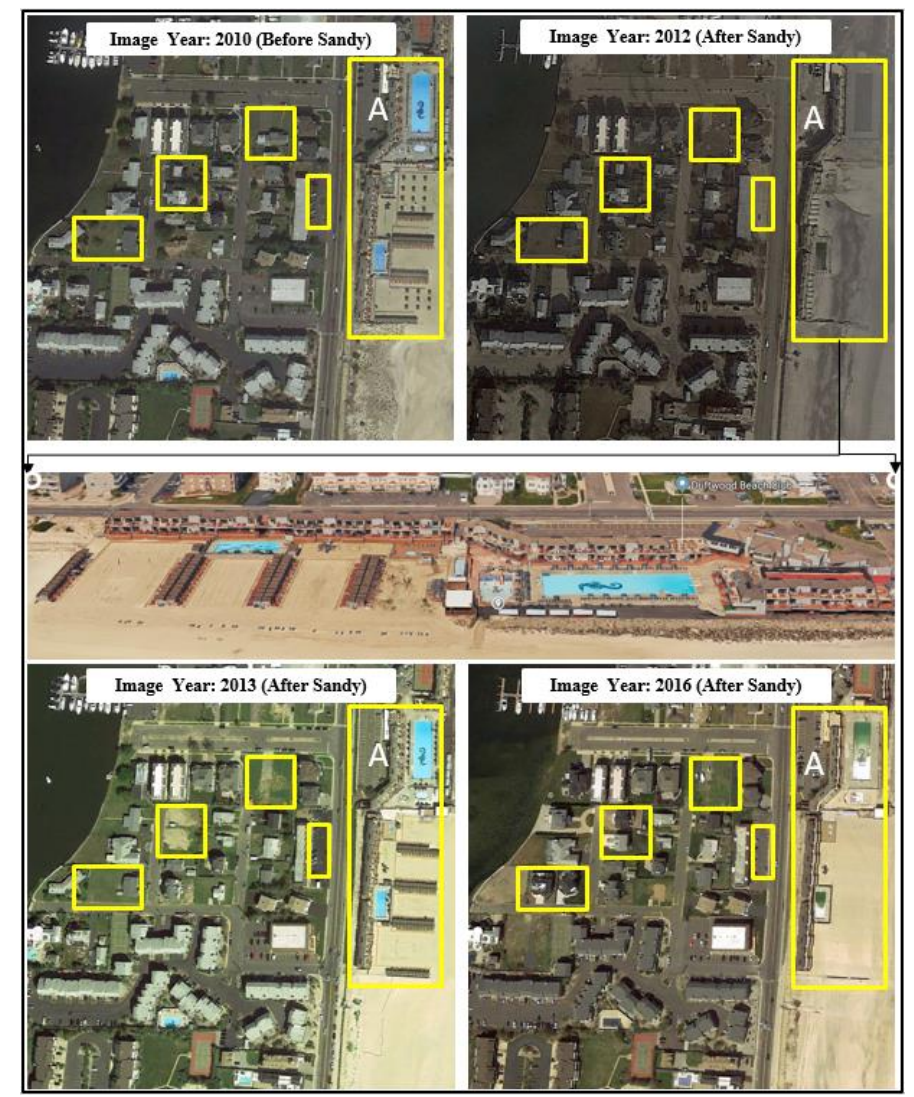

Figure 5. Visually identifiable changes in structural features (buildings) over time after Hurricane Sandy impact in 2012 (major impact on the Driftwood Beach Club).

From imagery, the changes in natural features such as the continuation of sandy dunes can be identified clearly. However, with buildings, the differences could only be detected if the property was fully destroyed or demolished for rebuilding and thereafter showed that the space had been either re-occupied with a different structure, or missing in one time interval and subsequently replaced in the next. In the case of the dunes naturally protecting Sea Bright, our study found that they were damaged in several places by Hurricane Sandy and were not repaired until 2016 (Figure 6). Figure 5A shows the Driftwood Beach Club that was completely destroyed in 2012. It was immediately rebuilt in early 2013 to prepare for the 2013 summer season. This club provides cabanas, decks, indoor pools, and other features for tourists.

Chronologically, comparing the building structures from the site images, it is found that 48 points had some change. Among them, 18 locations were fully destroyed, 18 had major damage, 9 had minor damage, and 3 were affected in that disaster. As of 2013, there was little activity to repair the destroyed properties, with only four properties rebuilt. This number increased to seven in 2014, while the remaining locations were still vacant plots. In 2013, eight plots with major damage were found vacant where building structures previously existed. In 2014, the number of vacant lots increased to 16, despite the reconstruction of houses on two of the previously vacant lots. Sites with minor damage also experienced demolition; for example, in 2014, seven of these locations were found to be unoccupied. The damage sites which were reconstructed and demolished, along with their damage condition 
from Hurricane Sandy, are shown in Figures 5 and 6. Figure 6 shows the Sea Bright Public beach, which offers lifeguards, rescue personnel, parking, restroom facilities and seasonal locker rentals. From the visual observation of the number of unoccupied plots and changes in use patterns shown in Figure 7, we can conclude that as of 2014, the southern section of Sea Bright was still undergoing the recovery process.

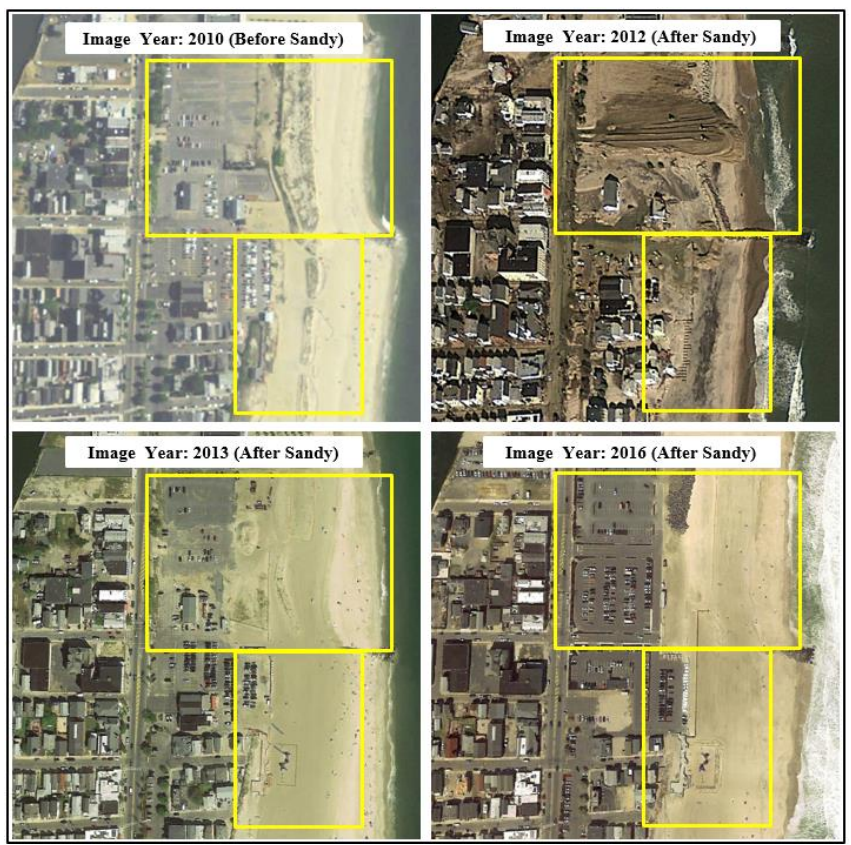

Figure 6. Condition of sandy dunes (Sea Bright Public beach) after Hurricane Sandy from 2010 to 2016.

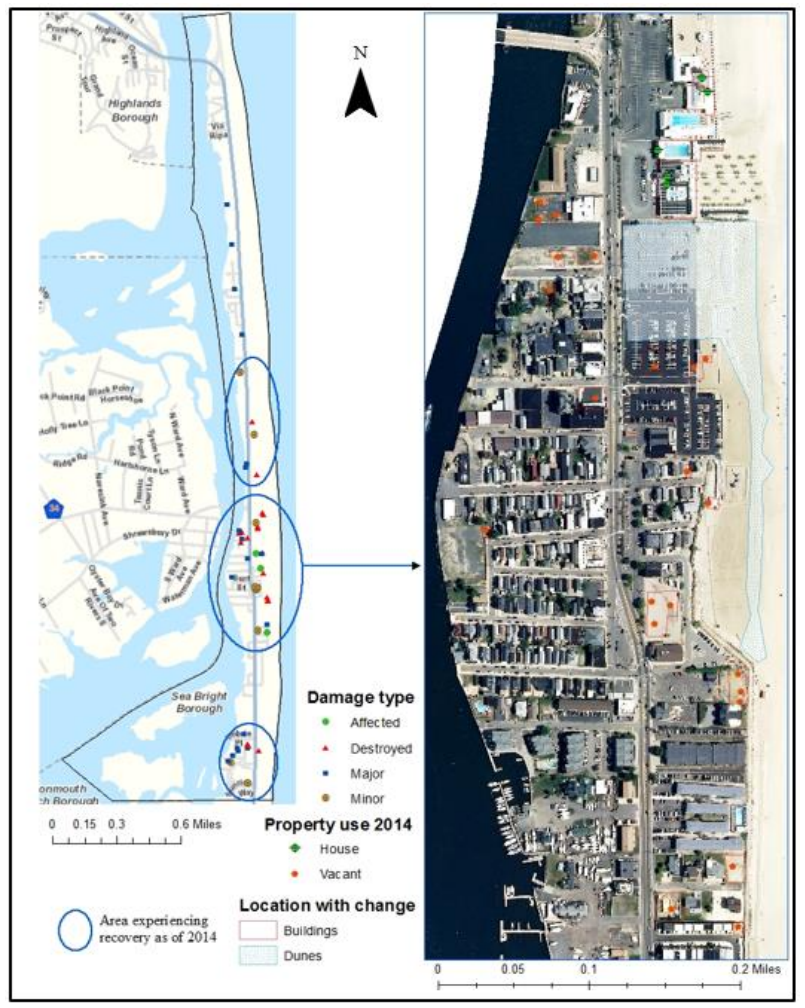

Figure 7. Locations of 48 damage points that showed changes after Hurricane Sandy, up to 2016. The concentration area identifies the location experiencing housing recovery. 


\subsubsection{Change Detection Using LiDAR Data}

The Quick Terrain Modeler (QTM) software was used to produce a 2-m resolution digital surface model (DSM) based on point spacing in pre- and post-disaster scenarios. Here 2-m was chosen to provide a good result, as it is greater than the point spacing in both data sets, and all points were covered in the surface creation. The surface models created from pre- and post-Hurricane Sandy elevation were used to identify the locations with differential change in elevation, thereby using loss or gain in elevation as an indicator of damage or debris accumulation in the area (Figure 8).
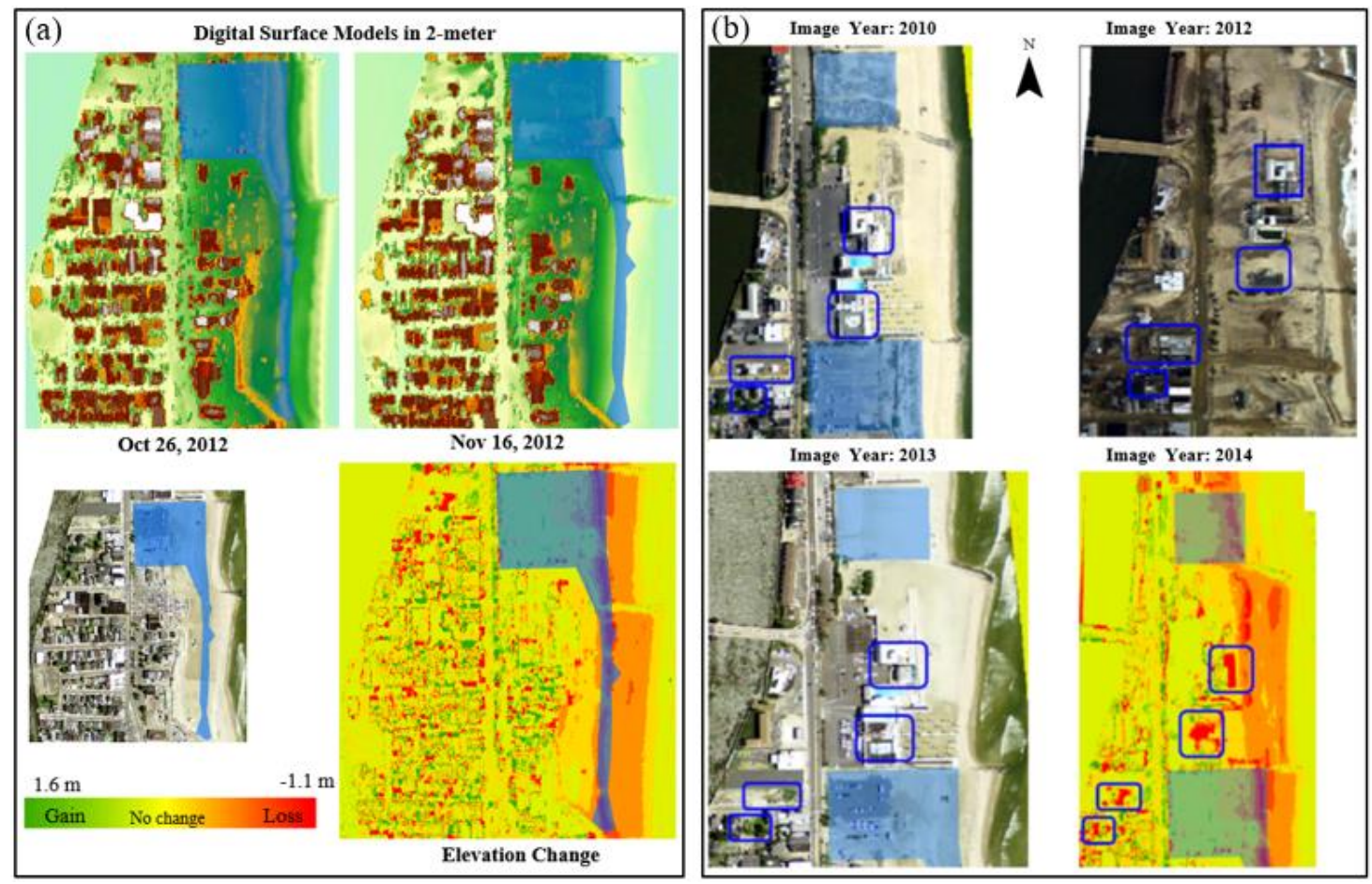

Figure 8. (a) Change detection in dunes pre- and post-Hurricane Sandy; (b) Change detection in building structures in pre- and post-Hurricane Sandy.

Figure 8 shows the visual interpretation from the LiDAR data analysis of change detection in pre- and post-Hurricane Sandy in natural dunes and building structures. To determine this change, the analysis tool "change detection map" in the QTM software was used to create a continuous surface showing elevation differences. These maps are useful in visually identifying the areas with gain or loss in elevation due to impact from Hurricane Sandy. This type of LiDAR data analysis is effective in damage estimation of an area when considering its physical properties.

\subsection{Progress in Recovery}

Recovery progress considers the changes in the number of damaged household properties. The main source of information to delineate progress is survey responses on "status of repair completed or not". If the repair was completed, it was counted as complete recovery with respect to structural damage. The change in the status of destroyed properties in Hurricane Sandy could be studied for different time intervals by visually noting the land use in those locations from satellite images in Google Earth. Google Earth satellite images are available through April 2014. Additionally, the properties labelled as "major or minor damage" or "affected" in Hurricane Sandy that were rebuilt after being demolished can be identified by observing the images in different times. 


\subsubsection{Property Status Comparing Survey Data and FEMA Damage Data}

The repair status of the buildings in the survey, as of August 2014, were compared to the initial damage reported by FEMA in order to determine the recovery level of the study area (Figure 9). Based on responses considering building repair, from addresses located within Sea Bright, $62 \%$ of the total damaged area was recovered in terms of building repair, and $38 \%$ of the area was in the process of recovery. Significant improvement was found in properties with minor damage, whereas $72 \%$ had completed repairs. The sites with major damage, along with destroyed plots, were experiencing slow recovery in 2014. As of August 2014, data showed 51\% of major damaged sites and $67 \%$ of all destroyed structures were still in the process of repair.

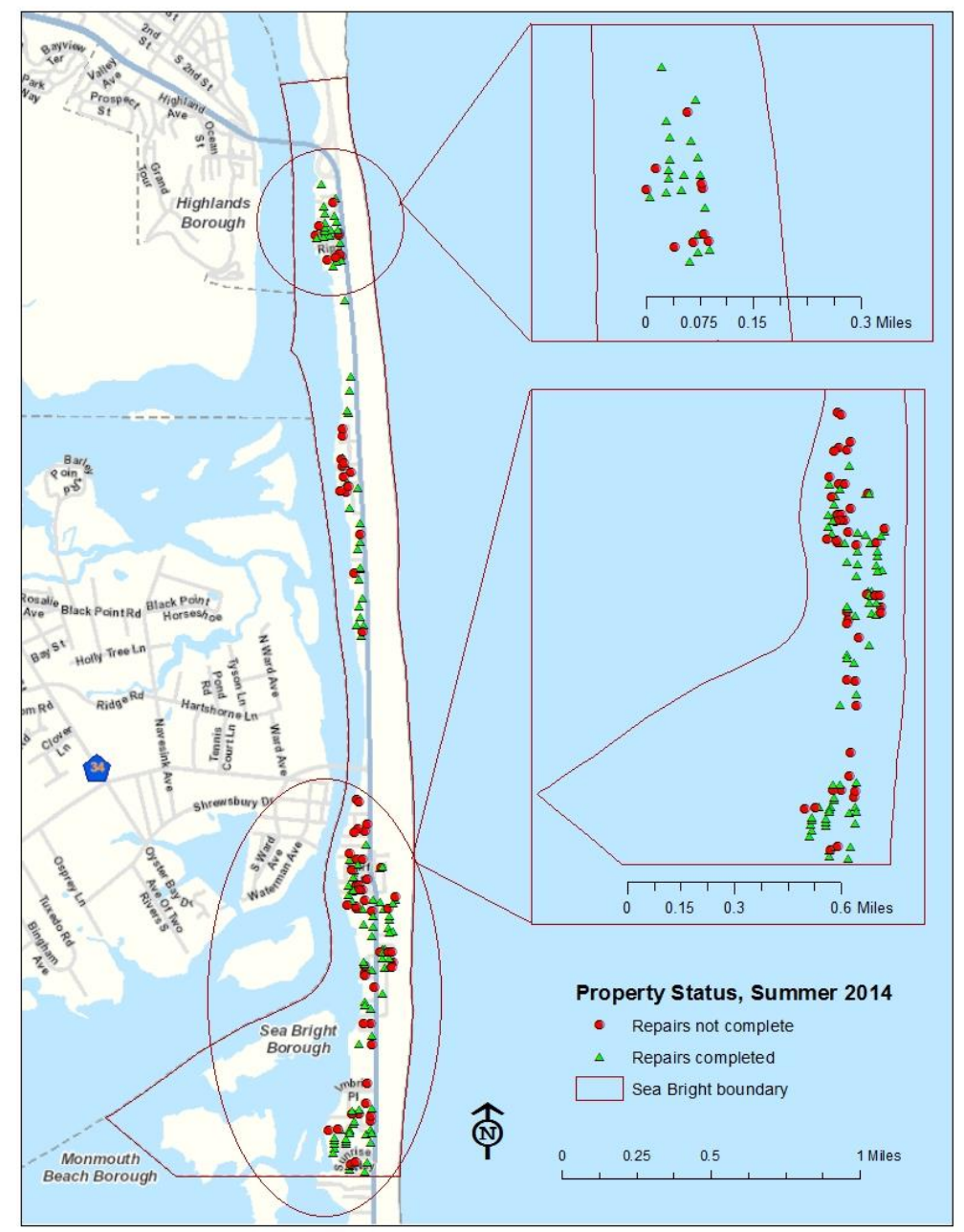

Figure 9. Recovery level of the study area based on repair status of the damaged buildings.

According to the damage category reported in the survey, $66.43 \%$ of repairs were completed, while the FEMA damage category and response of household survey showed $62 \%$ of the area under "repair complete" and were considered as fully recovered. These values are close enough to suggest consistency in the results, despite being calculated in different ways. Figure 9 shows the distribution of survey results on "repair completion" and locations where repair Was still needed. From Figure 9, it is apparent that there were no patterns in the progress of recovery based on location. Recovery had a mixed pattern throughout the borough. So, it cannot be said definitely which geographical location had fully recovered or had more recovery. If some damaged properties in one block had completed repairs, others may still have been waiting for repairs. 


\subsubsection{Recovery of Destroyed Property Assessed from Aerial and Satellite Imagery}

The recovery of destroyed properties could be verified by the visual inspection of sequential images in Google Earth. The georeferenced locations of destroyed plots were imported into Google Earth and their status was checked in the available time series after Hurricane Sandy made landfall in October 2012 until April 2014. This process allowed us to find the locations with or without development, and to assess the recovery process of these damaged properties.

Comparing the recovery among the damaged properties showed that the destroyed properties experienced slow recovery; although this observation is based on a small sample (from the survey, only 1 destroyed plot out of 3 reported completed repair). Examination of the satellite images from Google Earth, from October 2012, to 21 April 2014, showed 7 out of the 18 destroyed plots were in use (i.e., 38.89\%). The remaining destroyed plots were vacant, with no use. Figure 10 shows the trend line with percentage of recovery progress over total destroyed structures in the study area. The bar shows the number of vacant plots after Hurricane Sandy.

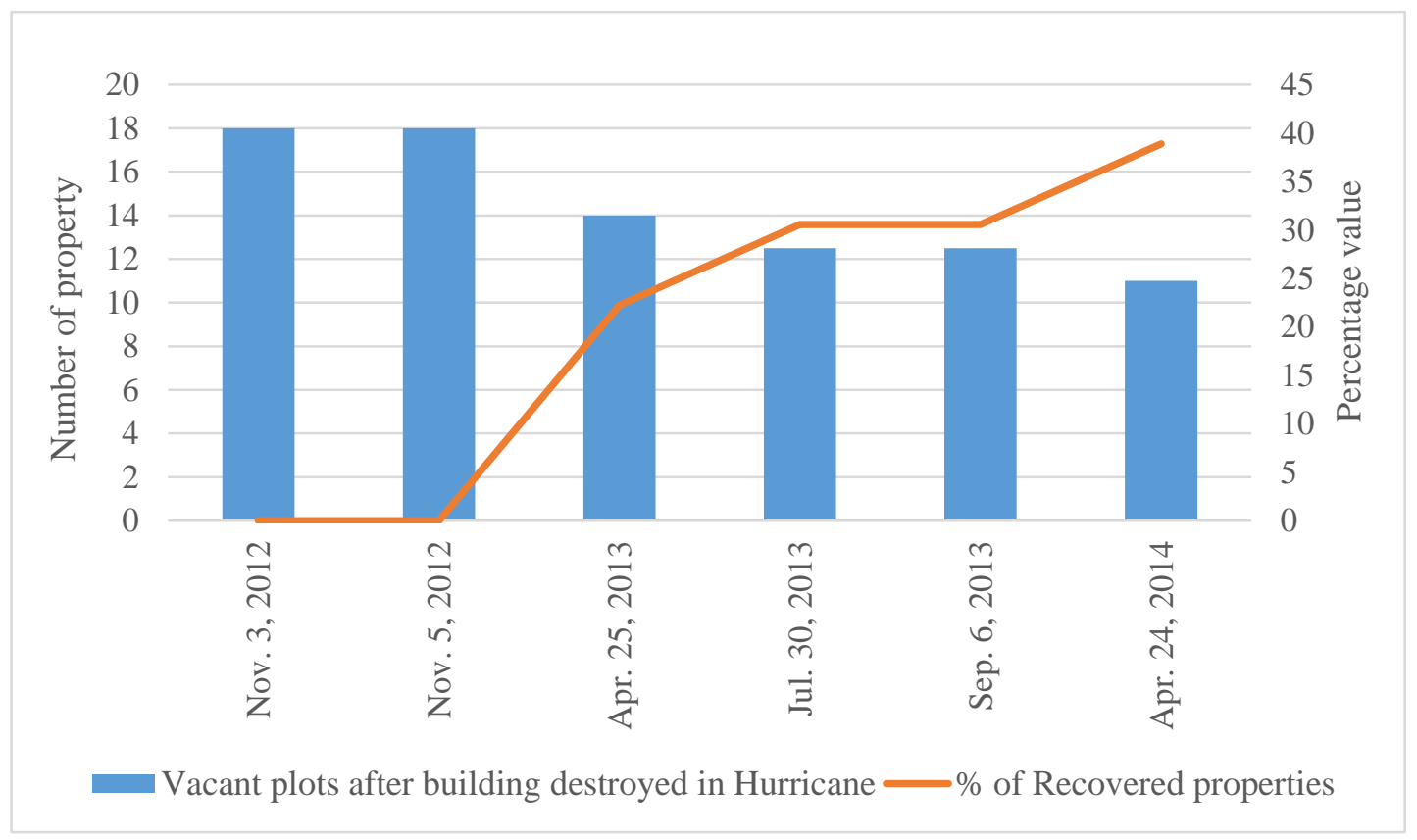

Figure 10. Recovery progress (\%) of the destroyed property with their status (vacant) in different time period in Sea Bright after Hurricane Sandy.

\subsubsection{Scaling Recovery in the Study Area}

The completion of the property repairs was assessed according to the same scale values as the damage, in order to assess the average recovery for the entire community. In this case, the number of respondents who claimed they had not completed repair was quantified: "not completed repairs number" was multiplied with the value of the specific damage category and then divided by the total number of damage structures to determine the impact in each damage group. All of these values were summed to give the average damage value for the whole study area. Table 3 shows the result from FEMA damage category of the responses located within Sea Bright. It was calculated from the equation for impact value of properties introduced in Section 3.2. As a result, the cumulative value for the area was 0.93 , so it was very close to "affected". In comparison, the value according to the damage category specified by the residents who responded in the questionnaire showed very close proximity to "not very extensive damage" of the entire community. 
Table 3. Quantifying repair of the damaged property to estimate the recovery level of the study area based on FEMA damage data and questionnaire damage type.

\begin{tabular}{cccccccccc}
\hline $\begin{array}{c}\text { FEMA } \\
\text { Damage } \\
\text { Record }\end{array}$ & $\begin{array}{c}\text { No. of } \\
\text { Damaged } \\
\text { Properties }\end{array}$ & $\begin{array}{c}\text { Repair Not } \\
\text { Complete }\end{array}$ & Scale & Impact & $\begin{array}{c}\text { Extensive Damage to } \\
\text { Home from Survey }\end{array}$ & $\begin{array}{c}\text { No. of Damaged } \\
\text { Properties }\end{array}$ & $\begin{array}{c}\text { Repair Not } \\
\text { Complete }\end{array}$ & Scale & Impact \\
\hline Affected & 22 & 7 & 1 & 0.04 & Not very Extensive & 73 & 29 & 1 & 0.104 \\
\hline Minor & 86 & 24 & 2 & 0.27 & Somewhat Extensive & 113 & 23 & 2.5 & 0.206 \\
\hline Major & 69 & 35 & 3 & 0.58 & Very Extensive & 93 & 41 & 4 & 0.588 \\
\hline Destroyed & 3 & 2 & 4 & 0.04 & Total & 279 & 109 & 0.898 \\
\hline Total & 180 & 68 & & 0.93 & & & & \\
\hline
\end{tabular}

Figure 11 schematically shows the position of the weighted recovery level considering FEMA damage categories and the survey responses' classification of damage. The responses related to repair completed or repair not completed was weighted to determine the status of the area as a whole. It is seen from the weighted result in Figure 11 that the whole area was very close to "affected". It is assumed that when the value reaches " 0 ", it can be said that the recovery is complete for the moment, considering the structural damage in the area.

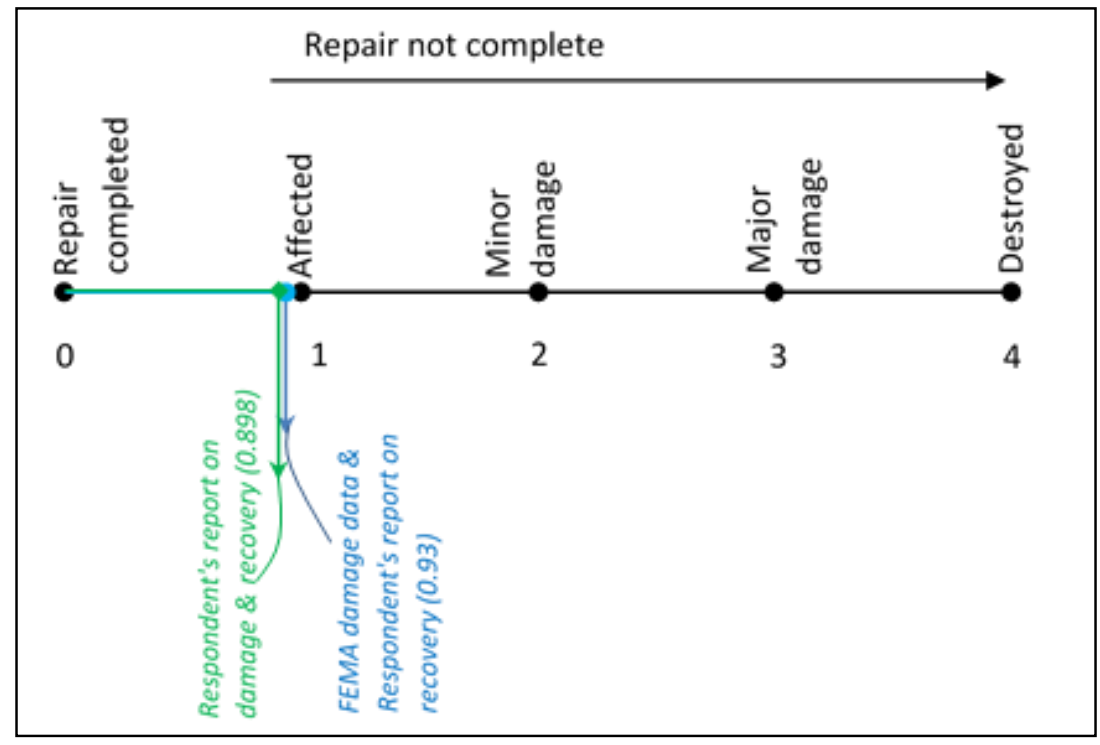

Figure 11. Schematic diagram showing the weighted recovery from different data sources.

\section{Discussion}

As stated earlier, coastal areas, especially sandy beaches, are important to the local economy because they tend to contain numerous natural and man-made tourism resources. However, their economies are highly dependent on weather conditions. According to Reference [35], after Hurricane Sandy, in Monmouth County, tourism spending in 2013 reached over $\$ 2.2$ billion. About 21,000 people in the County were employed in the tourism industry. Despite Hurricane Sandy, the County's tourism industry showed a 4.9 percent gain. Nearly half of tourism spending happened at the "Shore". Sea Bright's main industry is tourism, which drives the restaurant and beach club businesses. The town has stunning views and sandy beaches, making it a natural, highly-desirable platform for leisure and tourism. The town is acknowledged as a "bedroom community" because about 30 residents of the town work in the town, and approximately 450 travel into town for work. It is important to measure or estimate the level of damage after a disaster because damages to the physical features are directly relevant to the tourism industry. 
From the literature review, it is seen that recovery is the most uncertain and complex part of the disaster management cycle. It is very difficult to define disaster recovery using specific parameters. It is also difficult to declare an area, a community, or individuals as having fully recovered from the impact of previous disasters, unless the community starts working on a different phase or becomes impacted by another disaster. Therefore, this is a never-ending process. In general, considering the physical properties of an area; if the damaged buildings are repaired, reconstructed, or rebuilt; if the people restart their livelihood in their locality; and if the community begins to function as it did before the disaster, then it can be said that the area is recovering, and the process can be assessed to track the progress in one aspect-housing. Based on these findings, the recovery or management plan could be changed, modified, or updated to accelerate the recovery process or to be better prepared for future disasters.

Thus, this study emphasizes the development of a methodology that can be followed to identify the recovery progress rate in a tourism town. Our analysis showed that our results were almost identical when considering only 180 data responses with a postal address within Sea Bright or when considering all of the response data related to Hurricane Sandy. In addition, the FEMA-MOTF data were consistent with the results found from survey data. The findings of this research show that the entire locality of Sea Bright went through minor to major damage, as seen from the average damage score based on a scale for specific damage categories. However, considering the weighted value of recovery, the present condition of the area in 2014 was found to be at an "affected" level based on FEMA damage data and survey responses on repair. When comparing this value with respondents' damage category, the recovery of the study area was at a "not very extensive" damage level. One more step will move the community to full recovery with respect to structural damage and repair completion. The survey data gives good results, but the response size is small. It would have been better if more responses were obtained.

In contrast, the visual interpretation of satellite and airborne imagery shows very slow recovery progress in the completely destroyed plots. Only 39\% of the destroyed sites showed recovery regarding property redevelopment as of April 2014. Therefore, the more severe the damage, the more challenging the recovery. Again, many of the plots with major damage, and some of the minorly damaged and affected plots, showed as "rebuilt" starting approximately from mid-year 2013, and the "level of recovery" was increasing significantly as identified by visual inspection of images. This indicates that the recovery process was ongoing and the recovery level of a community can be changed depending on the recovery progress and the resources devoted to recovery. Analyzing data until 2014 using kernel density analysis of damage cost showed that the southern section of Sea Bright had more damage and a slower recovery than the northern section of Sea Bright. It is therefore important to capture the timeline in estimating the recovery level.

Lastly, it is difficult to handle a number of different types of data with several dimensions. This study struggled with data management and processing before running the analysis. LiDAR data requires intense processing before use. For the time being, only a surface model was created using LiDAR data to identify damage in loss or gain through change detection in elevation. Finally, it was learned from this research that assessing recovery is a difficult task due to the consideration of different types of data, with different measurement units (e.g., households versus structures).

\section{Conclusions}

This research proposed comprehensive assessment methods for the recovery of post-disaster housing and tourism resources. As part of the primary methods, public opinions were collected via a mail-based survey and quantitatively integrated into schematic diagrams showing the average damage and the weighted recovery from different data sources. This research helps policy makers or decision makers emphasize the locations identified as experiencing differential progress in the reconstruction, rebuilding, and repairing of houses or tourism resources. The proposed assessment methods need 
more public involvement regarding the post-recovery process. Thus, following research will develop a Web GIS-based survey system to promote public or community-engaged participation.

Author Contributions: B.Y. and I.J. developed the theory and the methods, performed the computations, and verified the analytical methods in this study. All authors discussed the results and contributed to the final manuscript.

Acknowledgments: The mail-based survey data were supported by the Disaster Research Center at the University of Delaware.

Conflicts of Interest: No potential conflict of interest was reported by the authors.

\section{References}

1. Page, S.; Connell, J. Tourism: A Modern Synthesis, 4th ed.; Cengage Learning EMEA: Andover, UK, 2014.

2. Orchiston, C.; Higham, J.E.S. Knowledge management and tourism recovery (de) marketing: The Christchurch earthquakes 2010-2011. Curr. Issues Tour. 2016, 19, 64-84. [CrossRef]

3. FEMA. Sandy Recovery Continues over the Holidays. 2014. Available online: http://www.fema.gov/ disaster / 4086/updates / sandy-recovery-continues-over-holidays (accessed on 20 June 2015).

4. Peacock, W.G.; Dash, N.; Zhang, Y. Sheltering and housing recovery following disaster. In Handbook of Disaster Research; Springer: New York, NY, USA, 2007; pp. 258-274.

5. Phillips, B.D.; Neal, D.M.; Webb, G. Introduction to Emergency Management; CRC Press: Boca Raton, FL, USA, 2011.

6. Faulkner, B. Towards a framework for tourism disaster management. Tour. Manag. 2001, 22, $135-147$. [CrossRef]

7. Smith, G.P.; Wenger, D. Sustainable disaster recovery: Operationalizing an existing agenda. In Handbook of Disaster Research; Springer: New York, NY, USA, 2007; pp. 234-257.

8. Rubin, C.B.; Saperstein, M.D.; Barbee, D.G. Community Recovery from a Major Natural Disaster; University of Colorado: Denver, CO, USA, 1985.

9. Geipel, R. Disaster and Reconstruction: The Friuli (Italy) Earthquake of 1976; Allen \& Unwin: London, UK, 1980.

10. Haddow, G.; Bullock, J.; Coppola, D.P. Introduction to Emergency Management; Butterworth-Heinemann: Oxford, UK, 2007.

11. Rathfon, D.; Davidson, R.; Bevington, J.; Vicini, A.; Hill, A. Quantitative assessment of post-disaster housing recovery: A case study of Punta Gorda, Florida, after hurricane charley. Disasters 2013, 37, 333-355. [CrossRef] [PubMed]

12. Barton, A.H. Communities in Disaster: A Sociological Analysis of Collective Stress Situations; Doubleday: New York, NY, USA, 1969.

13. Schwab, J. Planning for Post-Disaster Recovery and Reconstruction; Federal Emergency Management Agency: Washington, DC, USA; American Planning Association: Chicago, IL, USA, 1998.

14. Haas, J.E.; Kates, R.W.; Bowden, M.J. Reconstruction following disaster. In Reconstruction Following Disaster; US The Massachusetts Institute of Technology: Cambridge, MA, USA, 1997.

15. Olshansky, R.B. Toward a theory of community recovery from disaster: A review of existing literature. In Proceedings of the 1st International Conference of Urban Disaster Reduction, Kobe, Japan, 18-22 January 2005.

16. Quarantelli, E.L. Patterns of sheltering and housing in US disasters. Disaster Prev. Manag. 1995, 4, 43-53. [CrossRef]

17. Becker, W.S.; Stauffer, R.F. Rebuilding for the Future: A Guide to Sustainable Redevelopment for Disaster-Affected Communities; Department of Energy: Washington, DC, USA, 1994.

18. Thieler, E.R.; Bush, D.M. Hurricanes Gilbert and Hugo send powerful messages for coastal development. J. Geol. Educ. 1991, 39, 291-299. [CrossRef]

19. Nigg, J.M. Disaster recovery as a social process. In Wellington after the 'Quake': The Challenge of Rebuilding Cities; The Earthquake Commission: Wellington, New Zealand, 1995.

20. Chang, S.E.; Miles, S.B. The dynamics of recovery: A framework. In Modeling Spatial and Economic Impacts of Disasters; Springer: Berlin/Heidelberg, Germany, 2004; pp. 181-204.

21. Olson, R.S. Toward a politics of disaster: Losses, values, agendas, and blame. Crisis Manag. 2000, $18,154$. 
22. Olson, R.S.; Olson, R.A. "The rubble's standing up" in Oroville, California: The politics of building safety. Int. J. Mass Emerg. Disasters 1993, 11, 163-188.

23. Foley, D.L. The Sociology of Housing. Annu. Rev. Sociol. 1980, 6, 457-478. [CrossRef]

24. Berke, P.R.; Kartez, J.; Wenger, D. Recovery after disaster: Achieving sustainable development, mitigation and equity. Disasters 1993, 17, 93-109. [CrossRef] [PubMed]

25. Smith, G.; Birkland, T. Building a Theory of Recovery: Institutional Dimensions. Int. J. Mass Emerg. Disasters 2012, 30, 147-170.

26. Chang, S.E. Urban disaster recovery: A measurement framework and its application to the 1995 Kobe earthquake. Disasters 2010, 34, 303-327. [CrossRef] [PubMed]

27. Sword-Daniels, V.L.; Twigg, J.; Loughlin, S.C. Time for change? Applying an inductive timeline tool for a retrospective study of disaster recovery in Montserrat, West Indies. Int. J. Disaster Risk Reduct. 2015, 12, 125-133. [CrossRef]

28. FEMA. National Disaster Recovery Framework: Strengthening Disaster Recovery for the Nation. (Policy); Federal Emergency Management Agency, 2011. Available online: http:/ / www.fema.gov/media-librarydata/20130726-1820-25045-5325/508_ndrf.pdf (accessed on 20 May 2015).

29. Kaku, K.; Aso, N.; Takiguchi, F. Space-based response to the 2011 Great East Japan Earthquake: Lessons learnt from JAXA's support using earth observation satellites. Int. J. Disaster Risk Reduct. 2015, 12, 134-153. [CrossRef]

30. Morgan, J.; Begg, A.; Beaven, S.; Schluter, P.; Jamieson, K.; Johal, S.; Sparrow, M. Monitoring wellbeing during recovery from the 2010-2011 Canterbury earthquakes: The CERA Wellbeing Survey. Int. J. Disaster Risk Reduct. 2015, 14, 96-103. [CrossRef]

31. Stevenson, J.R.; Emrich, C.T.; Mitchell, J.T.; Cutter, S.L. Using building permits to monitor disaster recovery: A Spatio-temporal case study of coastal Mississippi following hurricane Katrina. Cartogr. Geogr. Inf. Sci. 2010, 37, 57-68. [CrossRef]

32. Zhang, Y.; Peacock, W.G. Planning for housing recovery? Lessons learned from Hurricane Andrew. J. Am. Plan. Assoc. 2008, 76, 5-24. [CrossRef]

33. Yang, B. GIS based 3-D landscape visualization for promoting citizen's awareness of coastal hazard scenarios in flood prone tourism towns. Appl. Geogr. 2016, 76, 85-97. [CrossRef]

34. Yang, B.; Lee, J. Improving accuracy of automated 3-D building models for smart cities. Int. J. Digit. Earth 2017, 1-19. [CrossRef]

35. Tourism Economics. The Economic Impact of Tourism in New Jersey. An Oxford Economics Company. 2014. Available online: https:/ / www.visitnj.org/sites/default/master/files/2014-nj-economic-impact.pdf (accessed on 20 May 2018).

36. McNeil, S.; Trainor, J.; Greer, A.; Jahan, I.; Mininger, K. Understanding the Relationships between Household Decisions and Infrastructure Investment in Disaster Recovery: Cases from Superstorm Sandy; Final Report; Center for Advanced Infrastructure and Transportation, Rutgers University: Piscataway, NJ, USA, December 2016.

37. FEMA-MOTF. Hurricane Sandy Impact Analysis. 2014. Available online: https:/ / content.femadata.com/ MOTF/Hurricane_Sandy/FEMA\%20MOTF-Hurricane\%20Sandy\%20Products\%20ReadME\%20FINAL. pdf (accessed on 20 June 2015).

38. HUD. Sandy Damage Estimates by Block Group. 2014. Available online: http://www.huduser.org/maps / map_sandy_blockgroup.html (accessed on 20 June 2015).

(C) 2018 by the authors. Licensee MDPI, Basel, Switzerland. This article is an open access article distributed under the terms and conditions of the Creative Commons Attribution (CC BY) license (http://creativecommons.org/licenses/by/4.0/). 